\title{
Simulation Analysis on Temperature Field and Temperature Stress of Flexible Pavement in Cold Areas
}

\author{
Wanzhu Zhen, Zihe Li \\ Forestry College of Beihua University, Jilin, China \\ Email: 771822190@qq.com
}

How to cite this paper: Zhen, W.Z. and Li, Z.H. (2021) Simulation Analysis on Temperature Field and Temperature Stress of Flexible Pavement in Cold Areas. Journal of Applied Mathematics and Physics, 9, 606-616.

https://doi.org/10.4236/jamp.2021.94044

Received: March 19, 2021

Accepted: April 17, 2021

Published: April 20, 2021

Copyright $\odot 2021$ by author(s) and Scientific Research Publishing Inc. This work is licensed under the Creative Commons Attribution International License (CC BY 4.0).

http://creativecommons.org/licenses/by/4.0/

\begin{abstract}
In order to ensure the service life of pavement in cold areas, this paper simulates the temperature field and stress field of pavement at high temperature of $60^{\circ} \mathrm{C}$ and low temperature of $-30^{\circ} \mathrm{C}$ based on ANSYS software, and analyzes the changing trend of temperature of each layer with time and the temperature stress caused by it using the time-incremental finite element method. The results show that when the temperature is higher than $0^{\circ} \mathrm{C}$, the temperature between layers of the structure and the surface temperature shows an increasing trend. On the contrary, when the temperature is lower than $0^{\circ} \mathrm{C}$, it shows a decreasing trend. The more drastic the temperature change is, the greater the temperature stress of the pavement will be, which is easy to cause road structure diseases. When the temperature difference of pavement reaches $90^{\circ} \mathrm{C}$, the change of temperature stress between layers of road structure has a significant effect on the daily evolution of pavement.
\end{abstract}

\section{Keywords}

Temperature Field, Stress, Pavement

\section{Introduction}

Northern China has distinct regional characteristics, and Jilin City of Jilin Province is the capital of rime. The paper takes the climatic conditions of Jilin City as an example, where the temperature could reach $34^{\circ} \mathrm{C}$ and the pavement temperature could reach $53^{\circ} \mathrm{C}$ in summer, while the temperature could reach $-30^{\circ} \mathrm{C}$ and the pavement temperature could reach $-33^{\circ} \mathrm{C}$ in winter. There is a big temperature difference between summer and winter, which greatly affects the temperature distribution of pavement structure. Pavement structure is placed in the 
natural environment and affected by temperature and the external environment changes, and the temperature between layers changes accordingly. The high and low temperatures of pavement will affect the performance of pavement structure and seriously affect the service life of the road. The paper uses transient thermal analysis method in ANSYS software to simulate the distribution of temperature changes between layers of pavement structure based on extreme temperature. Scholars at home and abroad have studied it. Based on the HMA pavement damage caused by heavy loads on highways in the United States as well as the SMP test site and the Virginia test pavement measurement temperature data, Diefenderfer [1] establishes the highest surface prediction model to meet the use requirements of any area. But there is no relevant research on the influence of temperature stress on pavement under no load. Ameri M [2] studies the asphalt pavement with transverse top-down cracks under traffic loads, and uses the three-dimensional finite element method to analyze and calculate the stress intensity factor (SIFS) and stress between the crack and the wheel at different distances. By studying the mechanism of rutting, Shang Lijun [3] finds that rutting sensitive area is correlated to stress field of asphalt pavement (positive stress field and shear stress field) and high temperature field, and determines the depth range of rutting sensitive area. The two scholars mainly take the failure and load as the research subject, and do not study the failure response under the influence of temperature. Taking the bridge deck pavement as the object, Wang Xantao [4] studies the problem that the maximum vertical deformation and the extreme principal stress of asphalt concrete pavement appear on the surface of pavement layer under static force and change with depth, and obtains the temperature distribution law of asphalt concrete bridge deck pavement. Yet bridge deck does not apply to the pavement. Taking the climate characteristic of high temperature and rain as an example, Baijian [5] concludes that the temperature field of the basic pavement varies periodically with the temperature and solar radiation, which could be represented by the attenuation exponential function model, and the time temperature curve shows obvious lag, but there is no relevant research on pavement temperature field in low temperature weather. Liu Kai [6] studies the relationship between the structural temperature field of different asphalt pavements and the environmental temperature, and establishes a prediction model of pavement temperature based on atmospheric temperature. There has been no study on the effect of temperature stress on flexible pavement in cold areas of Northern China. Taking Jilin City as an example, the paper uses numerical simulation to study the damage of temperature field and stress field on pavement under the temperature difference of $90^{\circ} \mathrm{C}$ in the case of large temperature difference between summer and winter in the cold northern region in China, as well as the damage effect of temperature field on asphalt pavement.

\section{Climate Research and Temperature Conversion}

The paper selects asphalt, a black pavement material that is more sensitive to temperature, as the research object to study and analyze the function relation- 
ship between the maximum temperature $T_{r(\max )}$ (minimum temperature $\left.T_{r(\min )}\right)$, the maximum temperature $T_{a(\max )}$ (minimum temperature $\left.T_{a(\min )}\right)$ and the daily total solar radiation $Q_{\phi}$ and uses research results in Reference [7] for conversion, as shown in Formula (1).

$$
\begin{aligned}
& T_{r(\max )}=-5.389+0.417 Q_{d}+1.45 T_{a(\max )}\left(R^{2}=0.97\right) \\
& T_{r(\min )}=-0.195+0.046 Q_{d}+1.045 T_{a(\min )}\left(R^{2}=0.98\right)
\end{aligned}
$$

The relationship between road temperature field and air temperature in the absence of total solar radiation is shown in Formula (2).

$$
\begin{aligned}
& T_{r(\max )}=1.5837 T_{a(\max )}-1.2470\left(R^{2}=0.93\right) \\
& T_{r(\min )}=1.0893 T_{a(\min )}+0.2146\left(R^{2}=0.92\right)
\end{aligned}
$$

According to the temperature conversion of Jilin City in January, March and July 2018 of China Meteorological Network, the pavement temperature is shown in attached Table 1.

The distribution changes of road temperature, air temperature and daily total solar radiation in Formula (1) and Formula (2) in January, March and July, as well as the changes in distribution of road temperature and air temperature when there is no sun in sight and total solar radiation are shown in Figures 1-3. Among them, $T_{r(\max )} Y_{1}$ and $T_{r(\min )} Y_{1}$ represent the maximum and minimum temperature of the total solar radiation when there is sun in sight, while $T_{r(\max )} Y_{2}$ and $T_{r(\min )} Y_{2}$ represent the maximum and minimum temperature of the total solar radiation when there is no sun in sight.

As shown in Figures 1-3, the comparison of temperature difference between temperature distribution of daily solar radiation pavement can be seen. The pavement temperature is low in January and March, and the sun radiation has no obvious effect on the pavement temperature. Yet under the influence of high temperature climate in July, pavement temperature has a serious impact on the change of pavement temperature with the increase of solar radiation quantity each day.

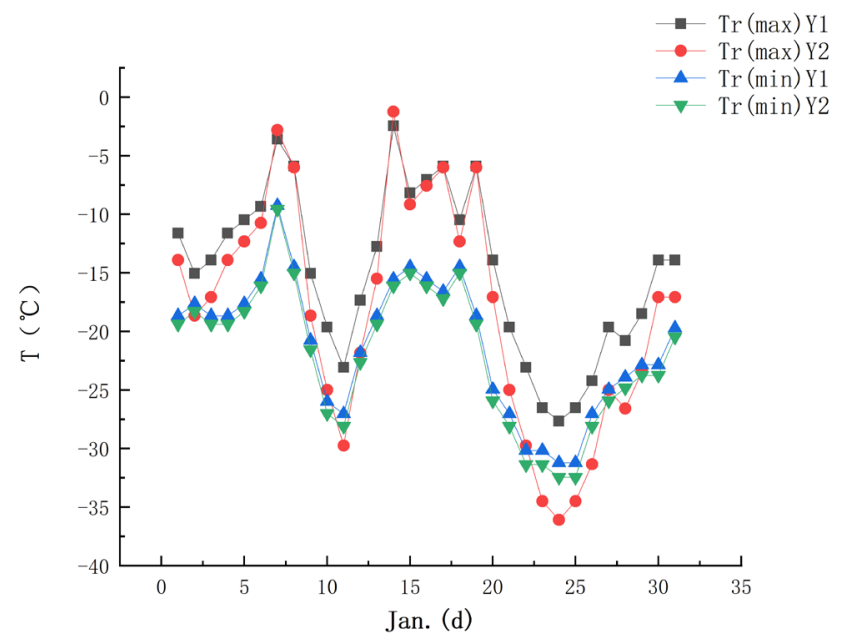

Figure 1. Solar radiation temperature distribution of asphalt pavement in January. 
Table 1. Temperature of road surfaces in January, March and July 2018.

\begin{tabular}{|c|c|c|c|c|c|c|}
\hline \multirow{2}{*}{ Date } & \multicolumn{2}{|c|}{ January $\left({ }^{\circ} \mathrm{C}\right)$} & \multicolumn{2}{|c|}{$\operatorname{March}\left({ }^{\circ} \mathrm{C}\right)$} & \multicolumn{2}{|c|}{ July $\left({ }^{\circ} \mathrm{C}\right)$} \\
\hline & $\operatorname{Tr}(\max )$ & $\operatorname{Tr}(\min )$ & $\operatorname{Tr}(\max )$ & $\operatorname{Tr}(\min )$ & $\operatorname{Tr}(\max )$ & $\operatorname{Tr}(\min )$ \\
\hline 1 & -11.6 & -18.7 & -7.2 & -16.2 & 37.3 & 21.5 \\
\hline 2 & -15.1 & -17.3 & -1.4 & -6.8 & 31.6 & 22 \\
\hline 3 & -13.9 & -18.7 & 5.4 & -12 & 35 & 22.2 \\
\hline 4 & -11.8 & -18.9 & -0.3 & -15.1 & 33.9 & 20.4 \\
\hline 5 & -10.5 & -17.6 & -8.3 & -17.2 & 32.7 & 18.3 \\
\hline 6 & -9.3 & -15.5 & -10.6 & -20.4 & 28.2 & 19.1 \\
\hline 7 & -3.6 & -9.2 & -4.9 & -15.1 & 31.6 & 19.4 \\
\hline 8 & -5.9 & -14.5 & -8.3 & -19.3 & 29.3 & 20.5 \\
\hline 9 & -15 & -20.8 & -7.2 & -11 & 31.6 & 20.8 \\
\hline 10 & -19.6 & -26 & -3.7 & -14.1 & 36.2 & 20.6 \\
\hline 11 & -23.1 & -27 & 0.8 & -10 & 35 & 23.6 \\
\hline 12 & -17.4 & -21.8 & 11.1 & -0.6 & 30.5 & 24.6 \\
\hline 13 & -12.8 & -18.7 & 13.4 & -0.5 & 35 & 25.7 \\
\hline 14 & -2.5 & -15.5 & 7.7 & -8.9 & 32.7 & 23.6 \\
\hline 15 & -8.2 & -14.5 & 2 & -12 & 35 & 25.7 \\
\hline 16 & -7 & -15.6 & 0.8 & -6.8 & 32.7 & 25.9 \\
\hline 17 & -5.9 & -17 & 9.1 & -2.6 & 37.3 & 26.1 \\
\hline 18 & -10.5 & -14.5 & 8.9 & -5.8 & 35 & 26.3 \\
\hline 19 & -5.9 & -18.7 & 0.8 & -7.9 & 37.3 & 26.7 \\
\hline 20 & -13.9 & -25 & 4.3 & -6.8 & 37.4 & 25.7 \\
\hline 21 & -19.6 & -27 & 8.9 & -7.1 & 39.2 & 25.7 \\
\hline 22 & -23.1 & -30.1 & 11.1 & -1.6 & 37.5 & 26.7 \\
\hline 23 & -26.5 & -31.2 & 14.6 & -0.5 & 39.6 & 25.8 \\
\hline 24 & -27.7 & -31.3 & 2 & 4.7 & 38.5 & 27.8 \\
\hline 25 & -26.5 & -27 & 22.6 & 4.9 & 37.3 & 23.6 \\
\hline 26 & -24.2 & -25 & 26 & 12 & 31.6 & 24 \\
\hline 27 & -19.6 & -24 & 27.2 & 7.8 & 35 & 22.6 \\
\hline 28 & -20.8 & -23.9 & 14.6 & 0.5 & 38.5 & 24.6 \\
\hline 29 & -18.5 & -22.8 & 13.4 & -0.6 & 39.6 & 25.8 \\
\hline 30 & -14.2 & -23 & 16.9 & 5.7 & 43.8 & 29.7 \\
\hline 31 & -13.9 & -19.7 & 17 & 3.6 & 38.5 & 27.1 \\
\hline
\end{tabular}

\section{Finite Element Analysis}

During the use of asphalt pavement, the joint action of air temperature and load is shown in Figure 4. The change of temperature is one of the main reasons affecting the performance of asphalt mixture, and many damages of asphalt 


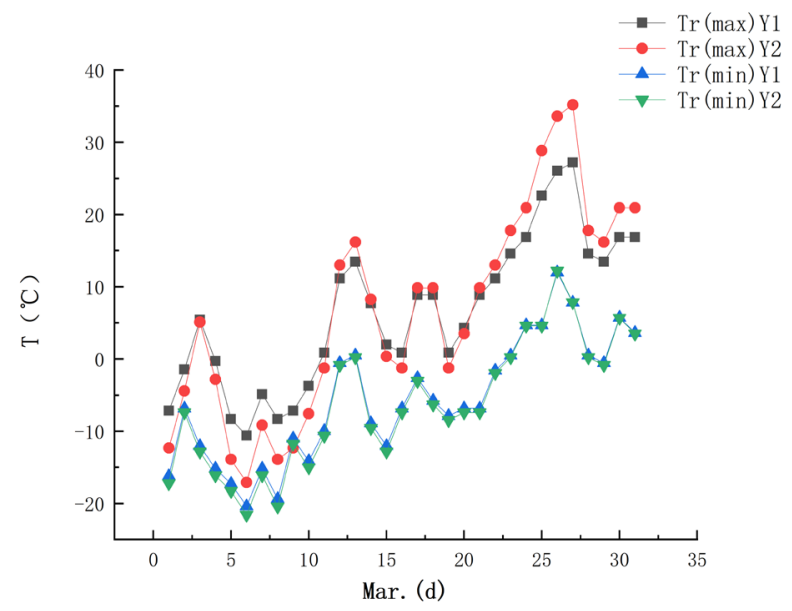

Figure 2. Solar radiation temperature distribution of asphalt pavement in March.

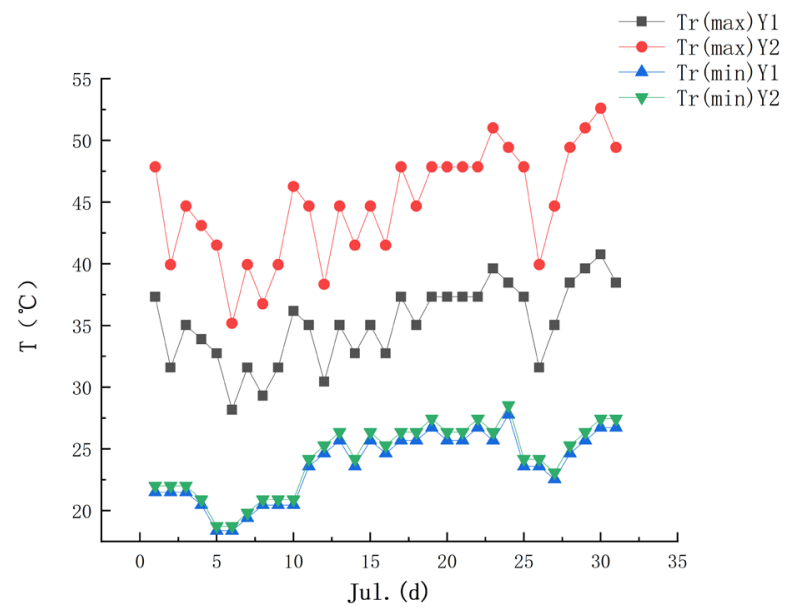

Figure 3. Solar radiation temperature distribution of asphalt pavement in July.

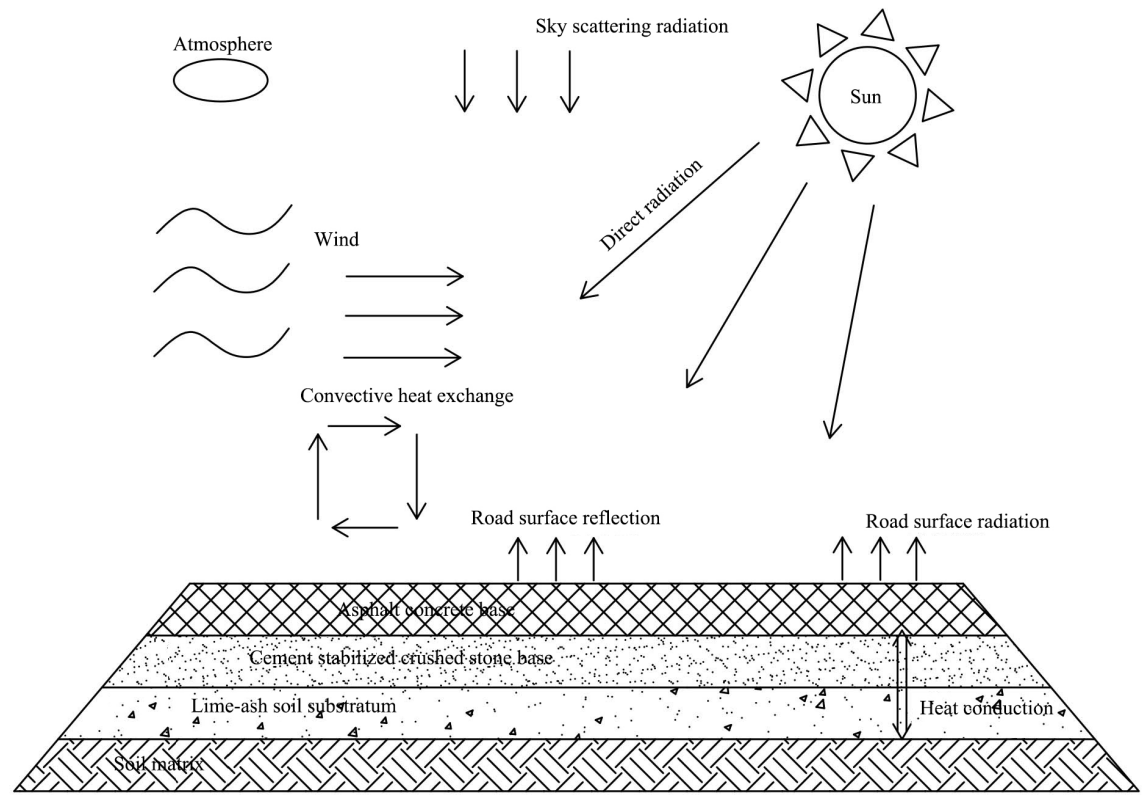

Figure 4. Diagram of the temperature exchange between the surface and the atmosphere. 
pavement (as shown in Figure 5) are related to temperature. Asphalt pavement is exposed to the natural environment and is affected by periodic climate conditions. The energy exchange between pavement and the external environment is completed by convection and radiation, and the energy exchange between road structures is mainly realized by heat conduction.

\subsection{Calculation Model}

Models of different sizes are analyzed and calculated, and the plane size studied in the paper is determined to be $6 \mathrm{~m} \times 5.5 \mathrm{~m}$. Assume that the road structure is an elastic layered system, and there are surface layer, base layer, cushion layer and soil foundation structure layer composition from top to bottom. The contact between the upper and lower layers is absolutely smooth, and the vertical and horizontal displacement, temperature and heat transfer between layers are all continuous. The overlay layers are completely continuous and the pavement layers are in close contact. A spatial three-dimensional model is established by simulation. Pavement structure layer is simulated with eight-node solid unit Thermal Solid Brick 8 Node 70. The coordinates of each point are shown in attached Table 2.

The model established by ANSYS software is shown in Figure 6 .

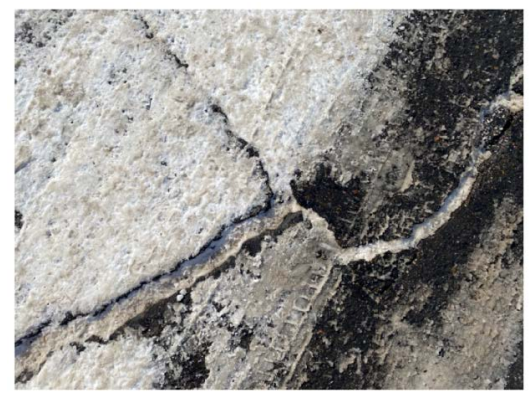

Figure 5. Asphalt pavement damage map.

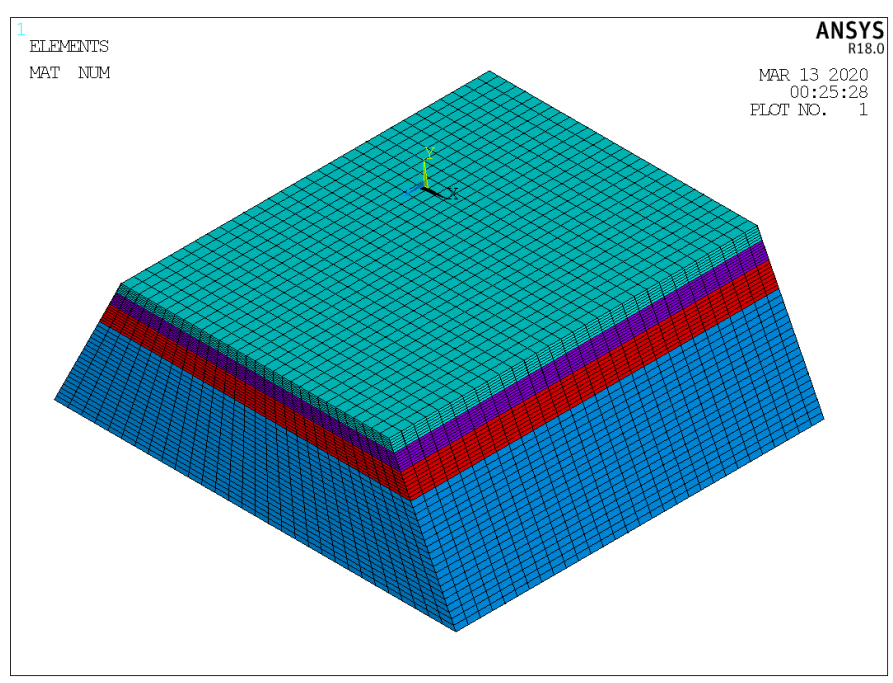

Figure 6. Finite element model of asphalt pavement temperature field. 
Table 2. Finite element model coordinate points.

\begin{tabular}{cccc}
\hline \multicolumn{4}{c}{ Coordinates } \\
\hline $1(0,0,0)$ & $2(600,0,0)$ & $3(600,0,550)$ & $4(0,0,550)$ \\
$11(100,200,0)$ & $12(500,200,0)$ & $13(500,200,550)$ & $14(100,200,550)$ \\
\hline
\end{tabular}

\subsection{Calculation Parameters}

The thickness of each layer of asphalt concrete in this paper is obtained by investigating the average thickness of pavement structure layers in Jilin City. The main calculation parameters of each structural layer of asphalt pavement are shown in Table 3.

\section{Results and Analysis}

The variation of stress of asphalt pavement temperature under extreme temperature is studied. The pavement structure temperature stress is analyzed at low temperature, room temperature and high temperature. The reference temperature of the road structure is $0^{\circ} \mathrm{C}$, and the pavement temperature rises to $60^{\circ} \mathrm{C}$, while the temperature drops to $-30^{\circ} \mathrm{C}$. The calculation results are shown in Figure 7 and Figure 8.

As can be seen from the figure, when the pavement temperature reaches $60^{\circ} \mathrm{C}$, the heat flow vector direction is upward and the pavement is in an exothermic state. The temperature changes between layers are obvious, and the maximum temperature is at the surface layer. When the temperature drops to $-30^{\circ} \mathrm{C}$, the negative heat flow vector direction is downward, and the pavement is in the state of heat absorption. The maximum temperature is in the red position of the soil base. That is, the surface temperature increases with time when it ranges from $0^{\circ} \mathrm{C}$ to $60^{\circ} \mathrm{C}$, and decreases with time when it drops from $60^{\circ} \mathrm{C}$ to $-30^{\circ} \mathrm{C}$.

As shown in Figure 9 below, Temp 2 is the trend of interlayer node temperature of surface layer $(0 \mathrm{~cm})$ changing with time. Temp 3 is the trend of interlayer node temperature of surface layer $15 \mathrm{~cm}$ changing with time. Temp 4 is the trend of interlayer node temperature of surface layer $20 \mathrm{~cm}$ changing with time. Temp 5 is the trend of interlayer node temperature of surface layer $30 \mathrm{~cm}$ changing with time. It can be clearly seen that the node temperature is different at different locations and depths. The surface layer temperature is the highest when the temperature is above $0^{\circ} \mathrm{C}$, and the lowest when the temperature is below $0{ }^{\circ} \mathrm{C}$.

The pavement is affected by solar radiation, air convection and heat exchange. The change of asphalt pavement temperature is most affected by air temperature, that is, the maximum temperature of pavement structure appears on the pavement, and the absorption rate of air to solar radiation is far less than that of pavement. Asphalt is a black temperature sensitive material, which is more sensitive to heat absorption, so the pavement temperature is much higher than the atmospheric temperature. 


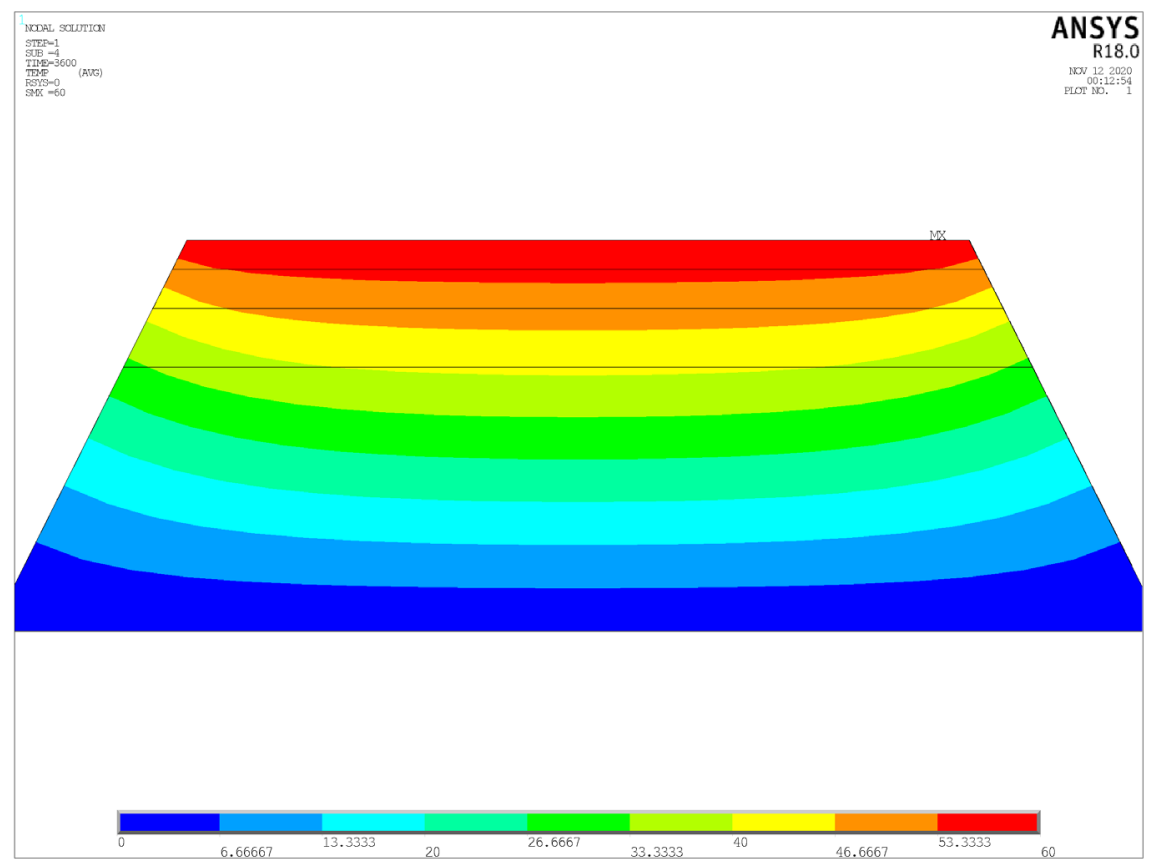

Figure 7. Contour map of temperature change of structural layer at $60^{\circ} \mathrm{C}$.

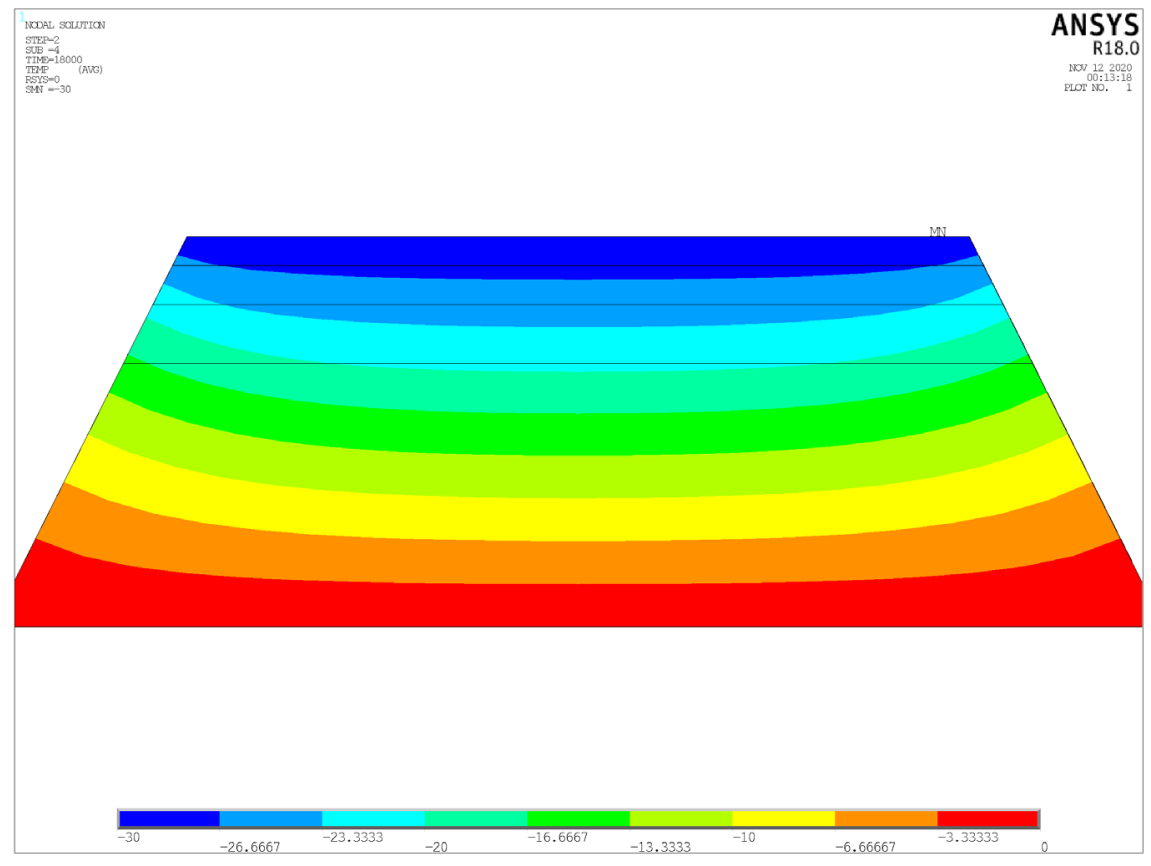

Figure 8. Contour map of temperature change of structural layer at $-30^{\circ} \mathrm{C}$.

Temperature stress changes from 0 to 2.51 at $0^{\circ} \mathrm{C}$ as shown in Figure 10 . Temperature stress between structural layers varies from 0 to 1.27 at $-30^{\circ} \mathrm{C}$, as shown in Figure 11. The greater the change of temperature, the greater the temperature stress of asphalt pavement, the greater the influence of structural modulus on the temperature stress. The maximum principal stress of the pavement is linearly related to the maximum shearing stress and modulus, that is, the optimum thickness keeps the temperature stress within a relatively low range. 


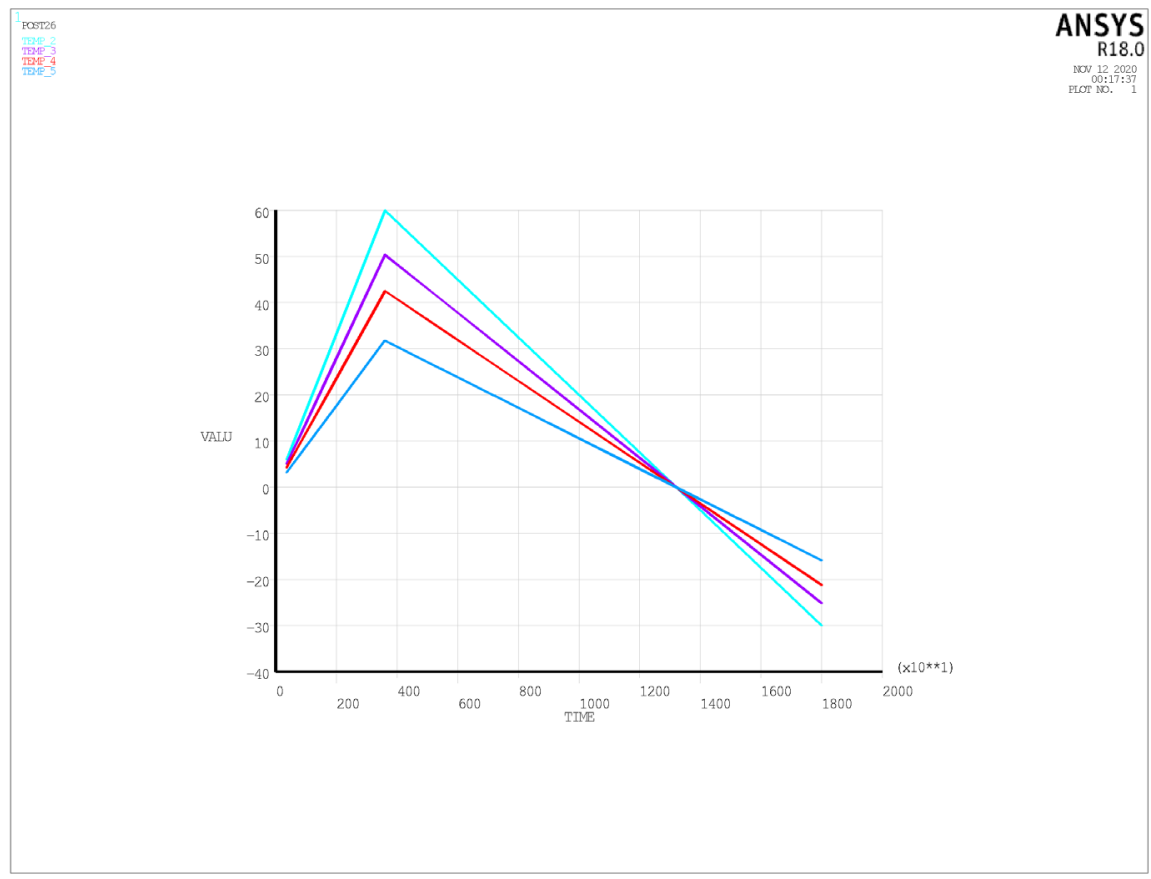

Figure 9. Temperature versus time of inter-layer nodes.

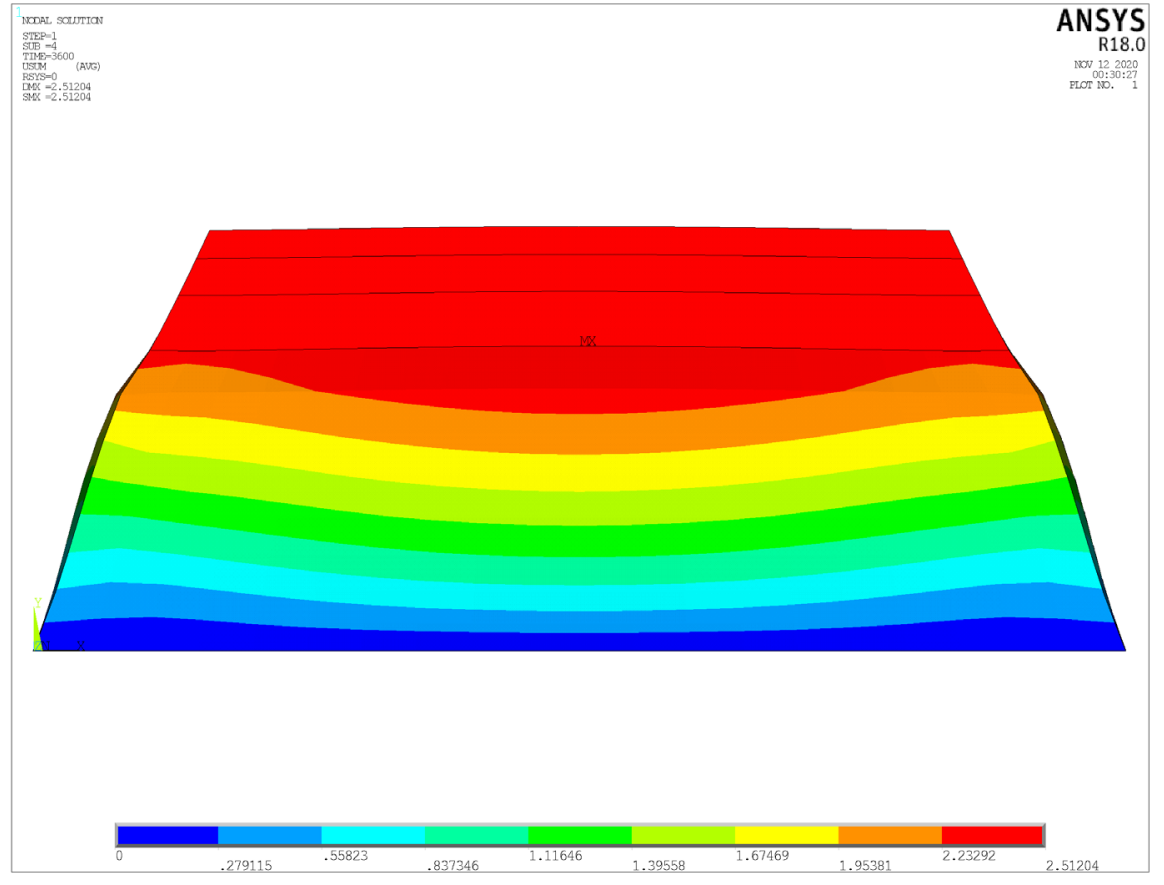

Figure 10. Contour map of temperature stress variation of structural layer at $60^{\circ} \mathrm{C}$.

The construction process requirements should be considered, that is, after paving and rolling, the pavement meets the compaction requirements, and the minimum thickness of the pavement should not be less than $4 \mathrm{~cm}$. Although the upper limit of pavement thickness is not specified, excessively thick pavement structure layers are costly and not economical. Therefore, the paper believes that considering the economical and mechanical requirements of the construction, in 


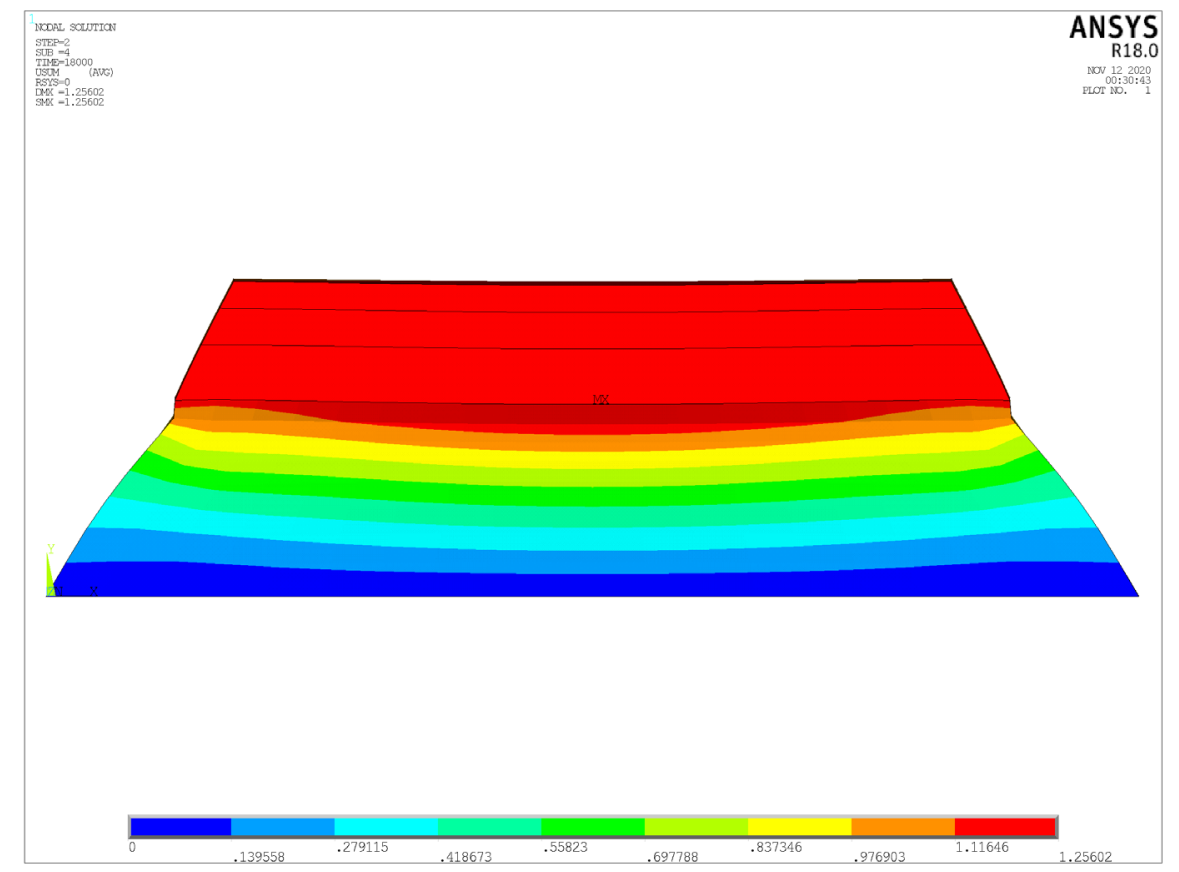

Figure 11. Contour map of temperature stress variation of structural layer at $-30^{\circ} \mathrm{C}$.

Table 3. Material parameters of pavement structures.

\begin{tabular}{cccccc}
\hline structural layer & $\begin{array}{c}\text { thickness } \\
(\mathrm{cm})\end{array}$ & $\begin{array}{c}\text { elasticity } \\
\text { modulus } \\
\mathrm{E}(\mathrm{MPa})\end{array}$ & $\begin{array}{c}\text { Poisson's } \\
\text { ratio } \mathrm{M}\end{array}$ & $\begin{array}{c}\text { heat conductivity } \\
\text { coefficient }\left(\mathrm{w} / \mathrm{m}^{\circ} \mathrm{C}\right)\end{array}$ & $\begin{array}{c}\text { Linear elasticity } \\
\text { coefficient }\left(1 /{ }^{\circ} \mathrm{C}\right)\end{array}$ \\
\hline $\begin{array}{c}\text { asphalt concrete } \\
\text { cement stabilized } \\
\text { macadam }\end{array}$ & 15 & 1800 & 0.25 & 1.0 & $2.0 \times 10^{-5}$ \\
$\begin{array}{c}\text { lime-ash soil } \\
\text { soil matrix }\end{array}$ & 30 & 1200 & 0.25 & 1.2 & $1.0 \times 10^{-5}$ \\
\hline
\end{tabular}

the area of large temperature difference, attention should be paid to the selection of materials with solar radiation absorption and thermal conductivity.

\section{Conclusions}

The paper selects the external environmental conditions of Jilin City as the research subject, determines the road material parameters suitable for the study, and establishes a model. Studies of domestic and foreign scholars show that there is no systematic study on road damage caused by pavement temperature stress. Based on the particularity of temperature environment, the paper analyzes the influence of big temperature difference on the pavement. The major conclusions of the paper are summarized as follows:

1) When the pavement temperature is $60^{\circ} \mathrm{C}$, the heat release of pavement structure affects pavement expansion. When temperature is $-30^{\circ} \mathrm{C}$, pavement shrinkage seriously affects pavement structure changes and pavement service life. The surface temperature is positively correlated with time from $0^{\circ} \mathrm{C}$ to $60^{\circ} \mathrm{C}$, 
and negatively correlated with time when it drops from $60^{\circ} \mathrm{C}$ to $-30^{\circ} \mathrm{C}$.

2) Through the study of pavement temperature field and temperature stress, it can be concluded that when the surface temperature difference reaches $90^{\circ} \mathrm{C}$, attention should be paid to the selection of materials with solar radiation absorption rate and thermal conductivity. In high-hazard locations, high elastic fiber materials should be added to increase the pavement stiffness and strength requirements. In view of the construction, economy and mechanical properties and requirements, the pavement materials should be reasonably selected according to the climatic characteristics of the cold northern region in China to reduce the damage to the pavement. It can satisfy the strength stiffness and improve the safety factor of the pavement so as to maximize the economic benefits.

\section{Conflicts of Interest}

The authors declare no conflicts of interest regarding the publication of this paper.

\section{References}

[1] Diefenderfer, B.K., Alqadi, I.L. and Diefenderfer, S.D. (2015) Model to Predict Pavement Temperature Profile: Development and Validation. Journal of Transportation Engineering, 132, 162-167. https://doi.org/10.1061/(ASCE)0733-947X(2006)132:2(162)

[2] Ameri, M., Mansourian, A., Khavas, M.H., et al. (2011) Cracked Asphalt Pavement under Traffic Loading-A 3D Finite Element Analysis. Engineering Fracture Mechanics, 78, 1817-1826. https://doi.org/10.1016/j.engfracmech.2010.12.013

[3] Shang, L.J. (2017) Stress Field Test of Asphalt Pavement and Analysis of Rutting Sensitive Areas. Master's Thesis, Chang'an University, Xi'an.

[4] Wang, X.T. (2018) Response Analysis of Bridge Deck Asphalt Pavement Based on Viscoelasticity and Interlayer Contact. Master's Thesis, Chang'an University, Xi'an.

[5] Bai, J. and Dou, H.B. (2019) Analysis and Simulation of Flexible Asphalt Pavement Temperature Field in High Temperature and Rainy Areas. New Building Materials, 46, 132-136.

[6] Liu, K. (2010) Study on Distribution Law of Asphalt Pavement Temperature Field. Master's Thesis, Chang'an University, Xi'an.

[7] Wang, Q., Wang, X.C. and Zhan, T. (2009) ANSYS-Based Temperature Field of Bridge Deck Pavement and Temperature Stress Simulation Analysis. Microcomputer Information, 25, 30-32. 